\title{
A randomized, comparative, open clinical trial for evaluating the efficacy of poly herbal suspension (JLN/PP/108) in comparison with conventional antacid gel in the management of functional dyspepsia and reflux oesophagitis
}

\author{
Padmanabha Rugvedi , K. Sridhar*, Vedula Sasibhushan, Rajiva Kumar Rai and J.L.N. Sastry \\ Dabur Research and Development Center, Dabur India Limited, Sahibabad, Ghaziabad-201010, Uttar Pradesh, India \\ *Pragati Biopharma Pvt Ltd, Jubilee Hills, Hyderabad-500028, Telangana State, India
}

\begin{tabular}{l} 
Article Info \\
\hline Article history \\
Received 10 May 2021 \\
Revised 27 June 2021 \\
Accepted 28 June 2021 \\
Published online 30 June 2021
\end{tabular}

\section{Keywords}

JLN/PP/108

GDSS

Hong Kong index

Likert scale

Non-ulcer dyspepsia

Reflux esophagitis

\begin{abstract}
Management of gastrointestinal reflux disorder and non-ulcer dyspepsia in Ayurveda is based on rich heritage of medical expertise using herbs and lifestyle changes. Multiple medicinal benefits in each herb make an Ayurvedic formulation, a comprehensive medicine in interrelated medical conditions. The objectives of the study were to evaluate the efficacy and safety of polyherbal suspension JLN/PP/108 in the management of functional dyspepsia (non-ulcer dyspepsia-NUD) and reflux esophagitis (gastroesophageal reflux disorder-GERD) in comparison to marketed antacid suspension.

JLN/PP/108 has godhumakshara, shatavari and putiha as active ingredients. Study was conducted in randomized controlled prospective open label design. Subjects $(n=60)$ were divided into 2 groups as per the inclusion criteria of NUD and GERD having 20 subjects and 10 subjects of NUD and GERD in each group, respectively. 10 subjects with positive endoscopy findings were present for each indication. Likert scale, glasgow dyspepsia severity score (GDSS) and Hong Kong index were used for clinical evaluation. Assessment was done at week 1 and week 2 of treatment and 2 weeks post treatment. JLN/ PP/108 and marketed antacid suspensions showed comparable effect in reducing the symptoms of dyspepsia. However, JLN/PP/108 scored over marketed antacid in terms of percentage reduction as well as over the symptom severity. JLN/PP/108 performed better than marketed antacid on Likert scale score and on GDSS and Hong Kong index scores as well. The product JLN/PP/108 was found to be statistically similar and therapeutically superior to marketed formulation and effective in the management of functional dyspepsia and reflux oesophagitis.
\end{abstract}

\section{Introduction}

The role of jatharagni or digestive fire is not only important for process of digestion but also for various physiological functions in the body as per Ayurveda. The metabolic activities are all influenced by Bhutagni and Dhatwagnis, the respective agents of individual element and tissues that are in turn dependent on the main Agni, the agni in Koshta or Jatharagni. Thus, derangement in the functions of Agni are to be dealt with effective remedies in both physiological and pathological conditions.

Agnimandya, can go unnoticed many a times without specific remedies as the symptoms may be vague. However, when symptoms like burning sensation in chest, sour eructation, indigestion, and bowel irregularities affect, it prompts specific treatment.

Since the invention of $H$. pylori as a specific causative agent for dyspepsia due to ulcers, the treatment principles of peptic ulcer have changed (Champion, 1997). Nowadays, though the incidence

Corresponding author: Dr. Padmanabha Rugvedi Principal Scientist, Dabur Research and Development Center, Dabur India Limited, Sahibabad, Ghaziabad-201010, Uttar Pradesh, India E-mail: padmanabha.rugvedi@dabur.com Tel.: +91-9844091822

Copyright $(\odot) 2021$ Ukaaz Publications. All rights reserved. Email: ukaaz@yahoo.com; Website: www.ukaazpublications.com of peptic ulcers is relatively less, the discomfort of dyspepsia still affects large number of people especially those who have wrong eating habits and lifestyle concerns.

Antacids used to neutralize the gastric hydrochloric acid raise the $\mathrm{pH}$ of the gastric contents to above 3.5 and give symptomatic relief of pain (in gastric and duodenal ulcers) by lowering the acidity and consequently relieving the muscle spasm. They do this by acting as weak bases (Moayyedi, 2017).

Non-systemic antacids like aluminium hydroxide gel, directly neutralize the gastric acid to give symptomatic relief whereas systemic antacids may be absorbed from the gut into the blood circulation and cause alkalosis, ex sodium bicarbonate (Moayyedi, 2017).

Antacids like magnesium hydroxide have mild laxative effect (e.g., magnesium hydroxide) and some are constipating (e.g., aluminum hydroxide). Systemic antacids can have impact on the calcium, phosphorous ions in circulatory system. Finally, antacids may affect the absorption of other drugs which may be administered along with antacids such as antichlolinergics and antibiotics (Moayyedi, 2003). Hence, an ideal antacid is expected to exert no or minimal side effects and provide better therapeutic benefits.

In this regard, polyherbal formulations are being studied for their effectiveness and safety in the management of GERD and NUD for 
symptomatic relief. Current study evaluates the safety and effectiveness of JLN/PP/108 as an effective remedy in GERD and NUD.

\section{Objectives of the study}

Primary objective was to evaluate the efficacy of JLN/PP/108 suspension in the management of functional dyspepsia and compare with marketed antacid suspension in the management of functional dyspepsia.

Secondary objectives were to evaluate the efficacy of JLN/PP/108 suspension in the management of reflux esophagitis and compare with marketed antacid suspension in the management of functional dyspepsia and to assess the safety and compliance of the JLN/PP/ 108 in subjects with functional dyspepsia and reflux esophagitis.

\section{Materials and Methods}

\subsection{Study subjects}

Total subjects $(\mathrm{n}=60)$ were divided into 2 groups (JLN/PP/108 suspension and marketed comparator suspension) as per the inclusion criteria of non-ulcer dyspepsia (NUD) and gastrointestinal esophageal reflux disorder (GERD) having 20 subjects and 10 subjects of endoscopically positive GERD in each group, respectively. The study was conducted at Pragati Sparsh Ayurvedic center, Hyderabad during year 2010. The study was approved by Institutional Ethics Committee before study initiation. The study has been retrospectively registered at Clinical Trial Registry of India (Reg. No. CTRI/2018/02/012101 Registered on: 23/02/2018).

NUD: Subjects of either sex aged 20-60 years with $\geq 24 \%$ of dyspepsia as per the Hong Kong index of dyspepsia with normal upper gastrointestinal endoscopy were included. In the event of patient undergoing treatment for dyspepsia, washout period of 1 week was mandatory.

Subjects with any clinical, or ultrasonographic evidence of organic disease that would account for the symptoms, suffering from peptic and duodenal ulcers or any severe systemic diseases, family history of peptic ulcer disease or gastric malignancy, subjects suffering from reflux oesophagitis and subjects with chronic NSAID and steroids (>1 month) use with or without evidence of an ulcer were excluded.

GERD: Subjects of either sex aged 20-60 years, suffering from, who complain signs and symptoms of reflux esophagitis like heartburn, regurgitation, for more than 25 per cent of the time for at least 1 Month were included. Subjects with grade o and grade I of GERD symptoms were included. Subjects with family history of peptic ulcer disease or gastric malignancy, subjects not giving consent for study required procedure like endoscopy, chronic NSAID use (> 1month) with or without evidence of an ulcer, subjects with clinically diagnosed serious medical illness (diabetes, SLE, rheumatoid arthritis, rheumatic arthritis, psoriatic arthritis), surgical illness, subjects on any other medication for the treatment of acidity other than specified in the study were excluded.

\subsection{Study end points}

Two weeks of intervention with JLN/PP/108 suspension in JLN/ PP/108 group and marketed antacid in comparator group was taken as therapeutic end point. Any improvement or relief from clinical symptoms related to acidity at the end of 2 weeks and 4 weeks or by the resolution of symptoms whichever stands early was considered as clinical end point. Formulation was to be immediately withdrawn from all the subjects showing any untoward effect attributable to the trial drug that was taken as primary safety endpoint.

\subsection{Investigational product}

All the subjects were advised to take JLN/PP/108 or comparator 2 teaspoonful $(10 \mathrm{ml})$ two times daily before food for 2 weeks as per randomization and, subjects were followed up for 2 weeks after treatment. JLN/PP/108 has Godhuma (Triticum sativum) kshara, Shatavari (Asparagus racemosus) and Mentha (Mentha piperata), as active ingredients. Comparator product has aluminium hydroxide, magnesium hydroxide and simethicone and sodium carboxymethyl cellulose as key ingredients.

\subsection{Parameters for clinical evaluation}

Likert scale was developed for the study with set of questionnaires for subjective assessment of clinical severity (Mogey, 1999). For global assessment of severity and clinical improvement, glasgow dyspepsia severity score (GDSS) (Omar, 1996) and Hong Kong index of dyspepsia (Hu, 2002) were employed.

Likert scale was developed as follows:

(a) To rate severity of upper abdominal pain and relief after therapy per visit,

(b) To rate severity of discomfort and relief after therapy per visit (upper abdominal fullness, early satiety, bloating, or nausea),

(c) Degree of worry about their condition (during enrolment), and

(d) Degree of concern that they might have a sinister underlying disease (during enrolment).

Seven point Likert scale is an example of a global assessment question: $0=$ None, $1=$ Minimal, 2 = Mild, 3 = Moderate, $4=$ moderately severe, $5=$ Severe, $6=$ Very severe.

\section{Results}

Out of the 30 subjects in group A, 22 were male (73\%) and 8 were female $(27 \%)$. The mean age of the group A is 41.53 years while that of male and female is 41.55 years and 41.50 years, respectively.

The score on Likert scale in group A was 10.80 (out of 24 points) at the baseline which was reduced to 6.23 at the end of visit 2 . The reduction was statistically significant $(p<0.05)$. The score was further reduced to 4.70 at the end of visit 3 . Whereas in group B, the mean average score on Likert scale was 11.23 (out of 24 points) at the baseline which was reduced to 9.10 and 7.70 at the end of visit 1 and visit 2 , respectively. The reduction was statistically significant $p=<0.05$. But, the score was further increased to 8.10 at the end of visit 3 .

The score on GDSS in group A was 13.27 at the baseline which was reduced to 8.47 at the end of visit 2 . The reduction was statistically significant $(p<0.05)$. The score was further reduced to 6.57 at the end of visit 3. In group B, it was 14.13 at the baseline which was reduced to 11.67 and 10.70 at the end of visit 1 and visit 2 , respectively. The reduction was statistically significant $p=<0.05$. But, the score was further increased up to 11.13 at the end of visit 3 . 
The mean score on Hong Kong index in group A was 32.23 (out of 60 points) at the baseline which was reduced to 24.60 at the end of visit 2 . The reduction was statistically significant $(p<0.05)$. The score was further reduced to 21.63 at the end of visit 3 . In group B, it was 34.87 (out of 60 points) at the baseline which was reduced to 28.80 at the end of visit 2 . The reduction was statistically significant $p=<0.05$. The score was further reduced to 30.50 at the end of visit 3 .

JLN/PP/108 suspension and marketed antacid suspension had shown comparable effect in reducing the symptoms of dyspepsia subjects. However, JLN/PP/108 scored over marketed antacid in terms of more $\%$ reduction as well as over the symptom severity. A summary of results of clinical assessment in all the scales in given in Figure 1 and Table 1.

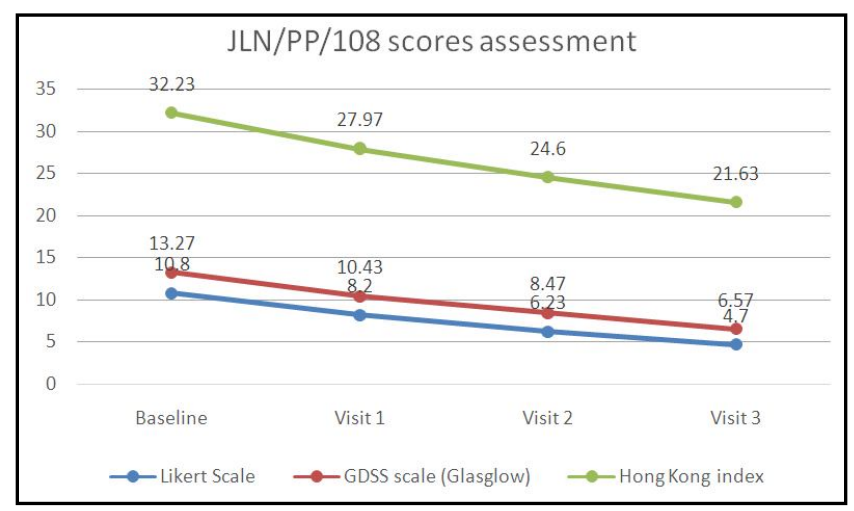

Figure 1: Clinical assessment based on various scores in JLN/ PP/108 group.

Table 1: Clinical assessment based on various scores in JLN/ PP/108 group.

\begin{tabular}{|l|l|c|c|c|}
\hline & Baseline & Visit 1 & Visit 2 & Visit 3 \\
\hline Likert scale & 10.80 & 8.20 & 6.23 & 4.70 \\
\hline GDSS scale & 13.27 & 10.43 & 8.47 & 6.57 \\
\hline Hong Kong index & 32.23 & 27.97 & 24.60 & 21.63 \\
\hline
\end{tabular}

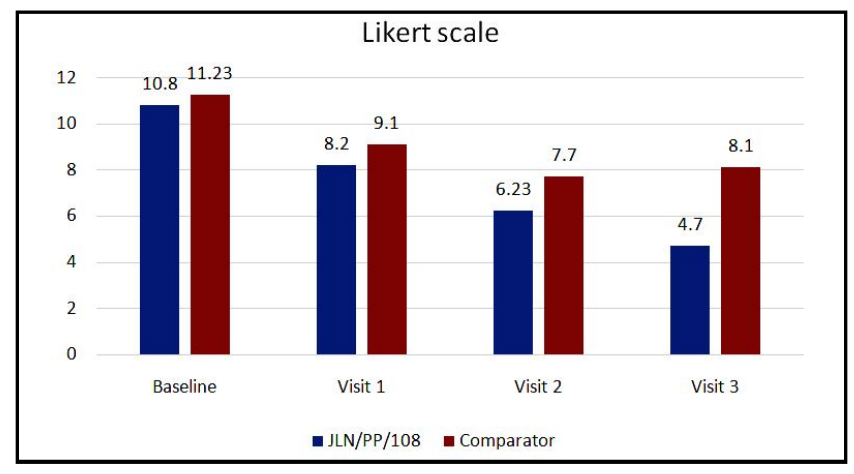

Figure 2: JLN/PP/108 performed better than marketed antacid on Likert scale score. There were 27 subjects $(90 \%)$ who felt relieved from symptoms at visit 2 in JLN/PP/ 108 group against 19 subjects $(63.33 \%)$ in comparator group.

In JLN/PP/108 group 10 subjects were endoscopically positive at baseline. Among them, 5 subjects shown normal study and 3 subjects shown improvement on endoscopy at visit 2. Another two subjects had no improvement on endoscopy. This confirms ulcer healing effect of trial drug JLN/PP/108. No subjects in the JLN/PP/108 group experienced any serious adverse effects. Four subjects in the comparator group complained of constipation.

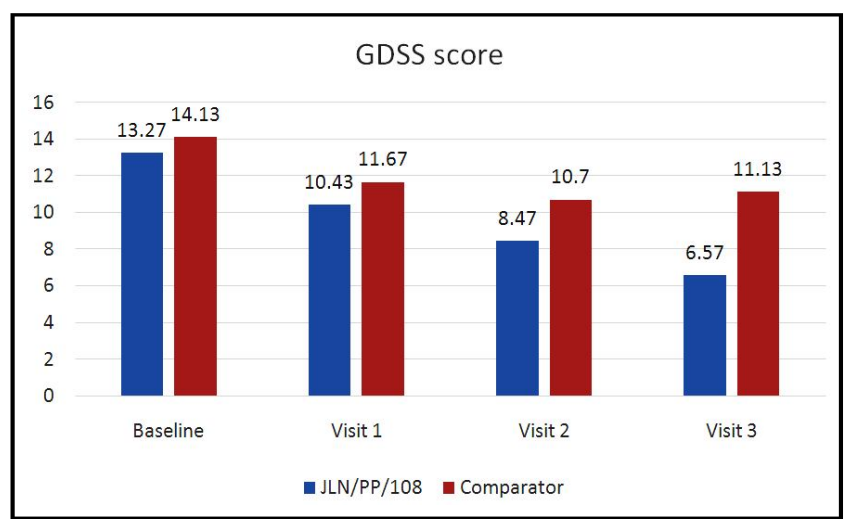

Figure 3: JLN/PP/108 performed better than marketed antacid on GDSS. There were 3 subjects $(10 \%)$ who were with severe symptoms of dyspepsia in JLN/PP/108 group against 14 subjects $(46.67 \%)$ in comparator group.

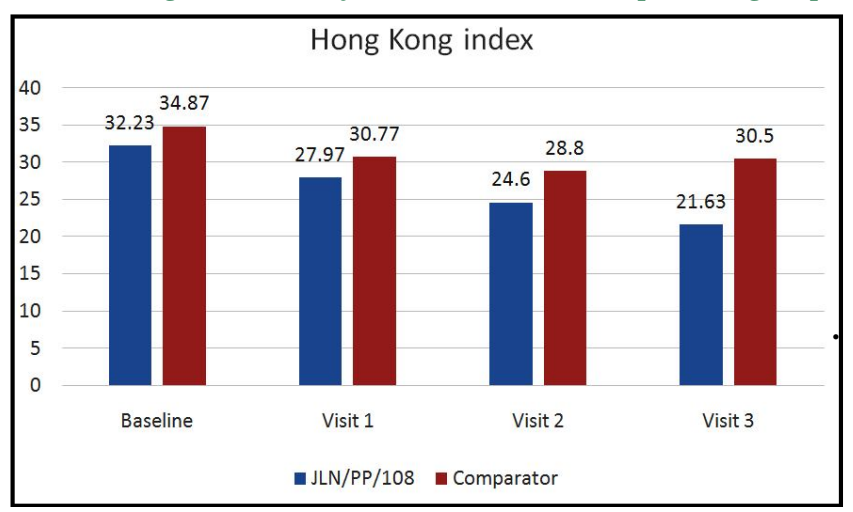

Figure 4: JLN/PP/108 also performed better than marketed antacid on Hong Kong index score. There were 27 subjects $(90 \%)$ who relieved from symptoms at visit 2 in JLN/PP/108 group against 19 subjects $(63.33 \%)$ in comparator group.

\section{Discussion}

The herbal ingredients composing JLN/PP/108 suspension are used in Ayurveda since thousands of years without any safety concern. Godhuma (Triticum sativum) is Madhura in rasa, Sheetal in virya, Snigdha in guna. It is considered as vata-pitaa-hara, jivaniya, ruchya (appetite stimulant). It is found to be useful in Annadravashula (acid-peptic disorders). (Pandey, 2006) Shatavari (Asparagus racemosus) is Madhura, tikta in rasa, Madhura in vipaka, Sita in virya, Guru, Snigdha in guna. It is considered as Balya (strength promoter), Rasayana (Rejuvenator), Pittahara, vatahara, Agnipushtikara. It is found to be useful in Gulma (abdominal lump), Parinam Sula (duodenal ulcer), Atisara (diarrhoea), Amlapitta (hyperacidity) (API, 2016). mentha (Mentha piperata) is Tikta, Katu in Rasa, Katu in Vipaka, Ushna in Virya, Tikta, snigdha, Laghu and Visada in Guna. It is found to be Dipana (appetizer), Pachana (digestive), Vatanulomak, Sulaprasamana, Kaphavatahara and found to be useful in Ajirana (dyspepsia), Aadhmana (flatulancae), Udarsula (pain in abdomen). (API, 2016) Mentha 
Spp are well known for the active ingredient with benefits for digestive system apart from being coolants (API, 2016).

Shatavari (Asparagus racemosus) is one of the choicest herb in Pitta disorders. It is shown effective relief from Amlapitta or hyperacidity symptoms in a clinical study evaluated in 32 patients by administrating the root powder $12 \mathrm{~g} / \mathrm{d}$ in four doses, for an average duration of 6 weeks. The ulcer healing effect of the drug was attributed as possibly by potentiating intrinsic protective factor as it has neither anti-secretory activity nor antacid properties. It acted mostly by strengthening mucosal resistance, prolonging the lifespan of mucosal cells, increasing secretion and viscosity of mucous and reducing $\mathrm{H}^{+}$ion back diffusion. It is also suggested that it may have cytoprotective action similar action to that of prostaglandin other binding of bile salts (Shashi, 2013).

Acharya Charaka mentioned Bhasma as well as Kshara together in the context of plant useful parts (Sastri, 2009). He further explained the side effects of excess use of Kshara in the 1st Chapter of Vimaanasthana (Sastri, 2009). He mentioned Sarjakshara and Yavakshara at several places. Acharya Charaka has also mentioned PaniyaKshara as a remedy for KoshtagataVata which has similar symptoms and help to improve the functions of both Agni and Vayu in Koshta. Sushruta dedicated special chapter for KsharaKalpana (Sastri, 1987). Further, he also explained about individual kshara effects in the 46th Chapter (Sastri, 1987). He classified Kshara as Pratisaraniya (external use) and Paniya (internal use). Acharya Vagbhata explained (Gupta, 2005) Kshara as Bahirparimarjana and Antahparimarjana. Texts of later period have described several sources (plants) for making Kshara.

Texts mention use of Sudharsarkara (lime crystals), addition of cow's urine, sankhachurna (calcium carbonate), etc., in the process of kshara preparation. The effort is to reduce the $\mathrm{pH}$ which varies between 11-13 to 8-8.5 in order to orally administer Paniya Ksharas.

There is no data on any Paniyakshara marketed as remedy for acid peptic disorders. So, this formulation may be a unique solution in the market with paniyakshara as an ingredient.

\section{Conclusion}

JLN/PP/108 relieves acidity, flatulence and alleviates symptoms such as belching, regurgitation, etc. In this, it is similar to marketed comparator. $(p>0.05)$. JLN/PP/108 also acts as ulcer-healing agent unlike marketed comparator. The relief on all the three scales by both the formulations is statistically highly significant $(p<0.001)$. $\mathrm{JLN} / \mathrm{PP} / 108$ is well tolerated than marketed comparator. JLN/PP/ 108 taste is better than that of marketed comparator. JLN/PP/108 did not cause any side effects like rebound hyperacidity or bowel irregularities. While constipation is reported with marketed comparator.

Therefore, JLN/PP/108 is statistically similar to and therapeutically superior to marketed comparator. Finally, it may be concluded that JLN/PP/108 performed better than marketed antacid suspension statistically as well as clinically. From the above results, it may be concluded that JLN/PP/108 is effective in the management of functional dyspepsia and reflux esophagitis.

\section{Acknowledgements}

Authors acknowledge Dr. Ruchi Srivastava MD (Ayu.) for her review and technical inputs on the article.

\section{Conflict of interest}

The authors declare that there is no conflicts of interest relevant to this article.

\section{References}

Champion, M.C. (1997). Prokinetic therapy in gastroesophageal reflux disease. Can. J. Gastroenterol., 11. Suppl., B:55B-65B

Chunekar, K.C. (2006). Commentary in Pandey G.S. (Ed) Bhavaprakasa Nighantu by Bhavamisra. pp:641 (2nd ed.). Chaukhamba Bharti Academy, Varanasi, India.

Gupta, A.K. (2005). Vagbhata'sAstangaSamgraha. Vol I. pp:254. ChaukhambhaKishnadas Academy. Varanasi, India.

Wayne, H.C. Hu.; Kwok-Fai, Lam.; Yeuk,Hing Wong.; Cindy, L.K. Lam.;Wai, Mo Huii.;Kam Chuen, Lai.; Benjamin, C.V. Wong and Shiu-Kum, Lam. (2002). The Hong Kong index of dyspepsia: A validated symptom severity questionnaire for patients with dyspepsia. J. Gastroenterol. Hepatol.,17(5):545-51. doi: 10.1046/j.1440-1746.2002.02713.x

Moayyedi, P.; Soo S.;Deeks J.; Delaney B.; Innes M and Forman D. (2003). Pharmacological interventions for non-ulcer dyspepsia. Cochrane Database Syst. Rev., (1):CD001960.

Moayyedi. P.; Brian, E. Lacy.; Christopher, N. Andrews.; Robert A. Enns.; Colin W. Howden and Nimish, Vakil (2017). ACG and CAG Clinical Guideline: Management of Dyspepsia, Am. J. Gastroenterol. Advance online publication, doi:10.1038/ajg.2017.154.

Mogey, N. (1999). "So You Want to Use a Likert Scale?". Learning Technology Dissemination Initiative. Heriot-Watt University. Retrieved April, 30:2009.

Omar, E.M.; Banerjee, S.;Wirz A. and McColl, K.E. (1996). The Glasgow Dyspepsia Severity Score: A tool for the global measurement of dyspepsia. Eur. J. Gastroenterol. and Hepataol., 8(10):967-971.

Sastri, A. (1987). Susruta Samhitha of Maharshi Susruta pp:34. Chaukhambha Sanskrit Sansthan, Varanasi, India.

Sastri, A. (1987). Susruta Samhitha of Maharshi Susruta. pp:187. Chaukhambha Sanskrit Sansthan, Varanasi, India.

Sastri, R. (2009). The Caraka Samhita of Agnivesa. pp:42. Chaukhambha Bharti Academy, Varanasi, India.

Sastri, R. (2009). The Caraka Samhita of Agnivesa. pp:678. Chaukhambha Bharti Academy, Varanasi, India.

Shashi, A.; Jain, S.K.; Verma, A.; Kumar, M.; Mahor, A. and Sabharwal, M. (2013). Plant profile, phytochemistry and pharmacology of Asparagus racemosus (Shatavari): A review. Asian. Pac. J. Trop. Dis., 3(3):242-251.

The Ayurvedic Pharmacopea of India (2016). Part I. Volume VI. pp:144147. Government of India, Ministry of Health and Family Welfare, Department of Indian System of Medical and Homoeopathy, New Delhi.

The AyurvedicPharmacopea of India (2016). Part I.Volume IV. pp:140-143. Government of India, Ministry of Health and Family Welfare, Department of Indian System of Medical and Homoeopathy, New Delhi. 